\title{
How far is the $\pi$-electron delocalization of the phenanthrene moiety modified in the aza-analogues and their $N$-oxides?
}

\author{
Beata T. Stępień, ${ }^{a}$ Tadeusz M. Krygowski, ${ }^{\text {a* }}$ Michał K. Cyrański, ${ }^{a}$ Jacek Młochowski, \\ Pierluigi Orioli, ${ }^{c}$ and Francesco Abbate \\ a) Department of Chemistry, University of Warsaw, L. Pasteura 1, 02-093 Warsaw, Poland, \\ ${ }^{b)}$ Wroclaw University of Technology, Institute of Organic Chemistry, Biochemistry and \\ Biotechnology, Wybrzėze Wyspiańskiego 27, 50-370 Wroclaw, Poland, ${ }^{c}$ University of Florence, \\ Department of Chemistry, Via Gino Capponi 7, I-50121 Florence, Italy \\ E-mail:tmkryg@chem.uw.edu.pl
}

\section{Dedicated to Professor Mieczysław Mąkosza, an outstanding Polish scientist, for his $\mathbf{7 0}^{\text {th }}$ birthday}

(received 27 Sep 03; accepted 20 Feb 04; published on the web 13 Apr 04)

\begin{abstract}
The consequences of the replacement of a $\mathrm{CH}$ fragment of phenantherene by N-aza, N-N-diaza and/or $\mathrm{N}$-oxide groups for the cyclic $\pi$-electron delocalization are discussed. Despite substantial structural changes, the $\pi$-electron structure is modified only moderately. The aza-analogues usually exhibit more effective $\pi$-electron delocalization, while the $\mathrm{N}$-oxidation leads to its decrease. Usually the presence of the nitrogen atom or $\mathrm{N}-\mathrm{O}$ group lead to more efficient delocalization in neighboring fragment(s). The analysis is based on experimental geometries of four phenanthroline $\mathrm{N}$-oxides and $\mathrm{N}, \mathrm{N}$-dioxides (4,7-phenanthroline 4-oxide, 1,7-phenanthroline 1,7-dioxide, 1,7-phenanthroline 7-oxide and 1,8-phenanthroline 1,8-dioxide) and is completed by the geometry optimizations with use of the DFT method at B3LYP/6-311G** level of theory.
\end{abstract}

Keywords: Aromaticity, phenanthrene, N-oxides, ab initio calculations, X-ray

\section{Introduction}

The phenanthroline and its N-oxides and N,N-dioxides attract much of interest because of their biological activities, ${ }^{1,2}$ complexation properties, ${ }^{3}$ inclusion in novel macrocycles, ${ }^{4}$ crystal engineering $^{5}$ and other possible applications. ${ }^{1,6}$ From the chemical point of view they are

\footnotetext{
* To whom correspondence should be addressed. FAX: (+48) 228222 892; E-mail: tmkryg@chem.uw.edu.pl
} 
derivatives of phenantherene, a smallest benzenoid hydrocarbon with a remarkable variation in the local $\pi$-electron delocalization. The $\pi$-electron structure of phenanthrene is well described by the Clar's aromatic sextet rule, ${ }^{7}$ which predicts two terminal rings as aromatic, and the central one as substantially less aromatic. This is consistent with chemical properties of the system: gradual hydrogenation leads firstly to 9,10-dihydro derivative. ${ }^{8}$ The geometry-based HOMA ${ }^{9}$ and magnetism-based NICS, ${ }^{10}$ descriptors, which are expected ${ }^{11}$ to deduce the stabilization due to cyclic $\pi$-electron delocalization most accurately, describe its electronic structure in a similar quantitative way, as presented in scheme $1 .{ }^{12}$

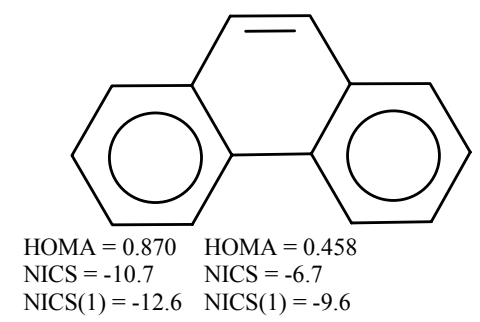

\section{Scheme 1}

The outer rings are clearly more aromatic than the central one, as indicated by more negative NICS and substantially higher HOMA values. The NICS (Nucleus Independent Chemical Shift) is defined as a negative value of the absolute magnetic shielding computed in centers of rings (denoted as NICS), or $1 \AA$ above of the molecular plane (denoted as NICS $(1)^{13}$ ). Negative NICS points to an aromatic system and the more negative it is, the more efficient the cyclic $\pi$-electron delocalization is expected to be. ${ }^{10}$ The other descriptor of the extent of the cyclic $\pi$-electron delocalization - HOMA (Harmonic Oscillator Model of Aromaticity) is defined as a normalized sum of squared deviations of bond lengths from the optimal value, ${ }^{9}$ which is assumed to be realized for a fully aromatic system. For benzene HOMA is equal to $0.98^{14}$ and admits 0 for a model non-aromatic system. ${ }^{9}$ The HOMA model has been successfully applied to many diverse $\pi$-electron systems. ${ }^{15}$ In particular it was useful to describe the local aromatic character of benzenoid hydrocarbons. ${ }^{12,16}$ The advantage of HOMA is that it may be applied as a descriptor of both local and global aromaticity. ${ }^{15 \mathrm{~d}}$ It has been well documented ${ }^{96,16,17}$ that the kind of connectivity of the rings, i.e. topological character, was the deciding factor ${ }^{17 \mathrm{~d}}$ about the extent of the $\pi$-electron delocalization of the ring in question. The replacement of $\mathrm{CH}$ groups by nitrogen atoms in the aza-analogues of benzenoid hydrocarbons significantly modifies the $\pi$-electron structure. ${ }^{18}$ The N-oxidation leads to further changes of the electronic structure as is reflected in aromaticity and reactivity. ${ }^{19}$ The aim of this paper is to systematically investigate the problem of the extent of changes in $\pi$-electron structure due to replacement of one or of two $\mathrm{CH}$ fragments of phenanthrene by nitrogen and/or NO groups. The analysis is based on our experimental geometries of four newly synthesized N-oxides and $\mathrm{N}, \mathrm{N}$-dioxides of phenanthroline (4,7phenanthroline 4-oxide, 1,7-phenanthroline 1,7-dioxide, 1,7-phenanthroline 7-oxide and 1,8phenanthroline 1,8-dioxide) and is completed by the geometry optimizations with use of the DFT method at B3LYP/6-311G** level of theory. ${ }^{20}$ 


\section{Results and Discussion}

The molecular structure of 4,7-phenanthroline 4-oxide, 1,7-phenanthroline 1,7-dioxide, 1,7phenanthroline 7-oxide, 1,8-phenanthroline 1,8-dioxide and phenanthrene is shown in Figure 1.

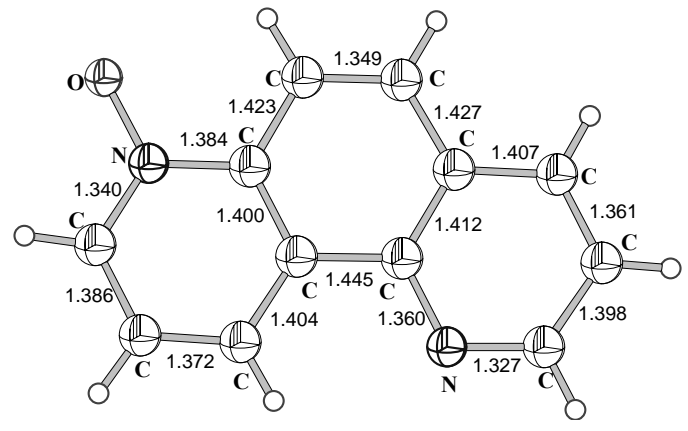

(a)

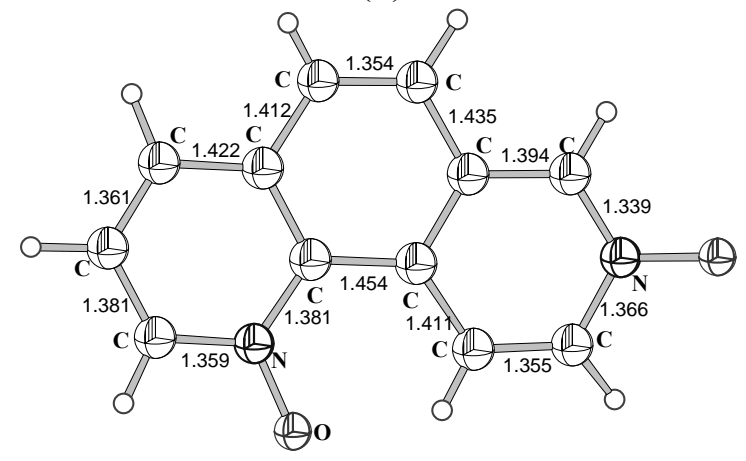

(c)

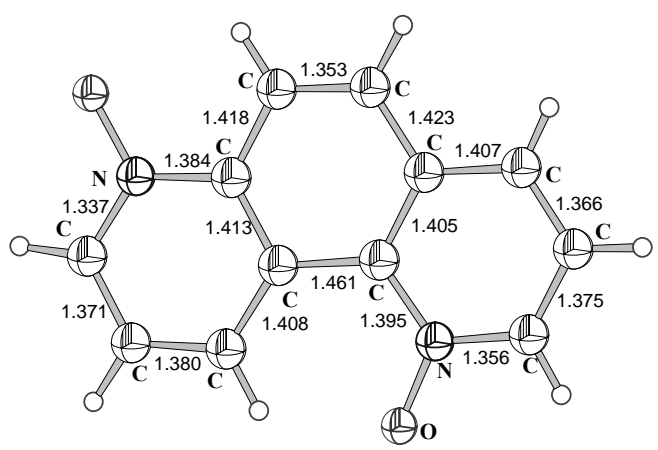

(b)

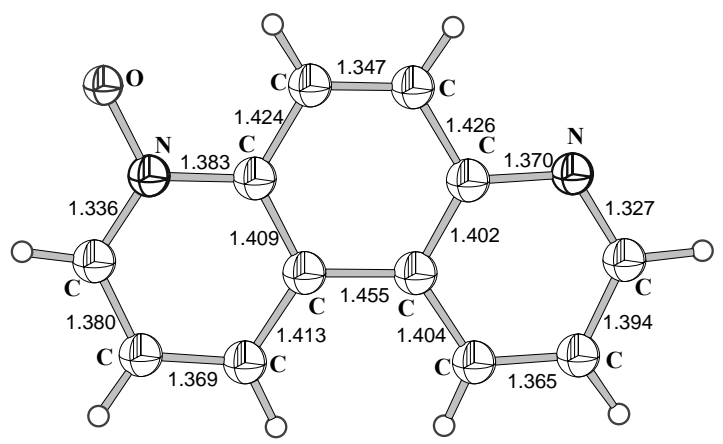

(d)

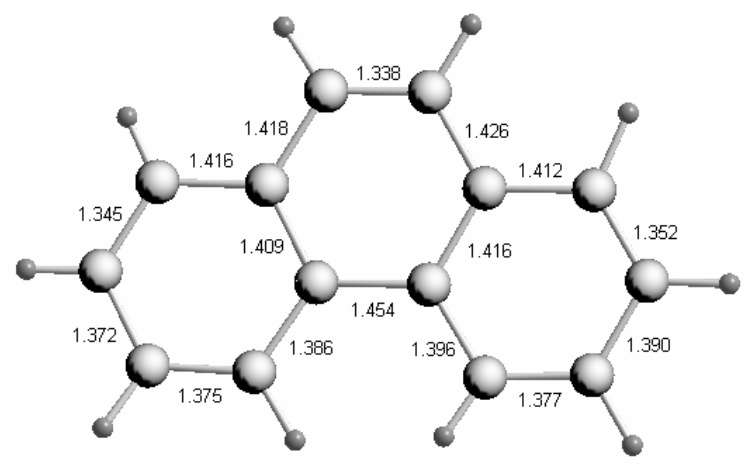

Figure 1. The molecular structure of 1,7-phenanthroline 7-oxide, ${ }^{21}$ (a), 1,7-phenanthroline 1,7dioxide, ${ }^{21}$ (b) 1,8-phenanthroline 1,8-dioxide ${ }^{21}$ (c), 4,7-phenanthroline 4-oxide, ${ }^{21}$ (d) and phenanthrene ${ }^{22}(\mathbf{e})$.

Clearly in all these systems there is a remarkable variation of bond length both of the central and of the outer rings. In the phenanthrene the variation of bond lengths ranges between 1.338 to $1.454 \AA$ for the central fragment and between 1.345 and $1.416 \AA^{22}$ for the outer ones. Moreover, the system has no $C_{2 v}$ symmetry and the deviations caused by crystal packing forces between the 
equivalent bond lengths are even $0.018 \AA$, which indicated high flexibility of its electronic structure. Such great difference can be also a result of a disorder in the crystal lattice. ${ }^{22}$ Importantly, the substitution by $\mathrm{N}$-oxide groups do not lead to dramatic changes in geometry, at least in the $\mathrm{CC}$ fragment. For instance the differentiation of bond lengths in the central rings varies between 1.353 and $1.461 \AA$. This is signifficantly smaller as compared with the phenanthrene parent system. Similarly, in the outer rings the deviations of bond lengths as compared with phenanthrene are not high despite of the closest neighborhood of the $\mathrm{N}-\mathrm{O}$ group(s). The HOMA calculated for these systems show that the cyclic $\pi$-electron delocalization is not destroyed but rather enhanced. The global aromaticity (estimated on experimental geometry) of phenanthrene ${ }^{22}$ is 0.750 . This is in excellent agreement with the value estimated on B3LYP/6-311G** optimized geometry $\left(\mathrm{HOMA}=0.741^{12}\right.$ ). Despite high modifications of the system in 1,7-phenanthroline 7-oxide, 1,7-phenanthroline 1,7-dioxide, 1,8-phenanthroline 1,8dioxide, 4,7-phenanthroline 4-oxide the extent of delocalization is higher: $0.821,0.779,0.768$ and 0.794 , respectively. Moreover, local aromaticities indicate that the extent of changes is appreciably higher for the central fragment as compared with the outer ones (See Fig. 2). The increase of aromaticity of the central ring ranges from 0.130 to 0.188 of unit of HOMA for 1,7phenanthroline 1,7-dioxide, (b) and 1,7-phenanthroline 7-oxide, (a), respectively.

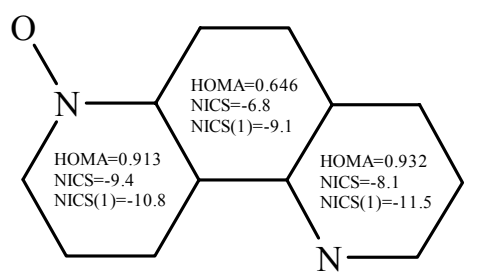

(a)

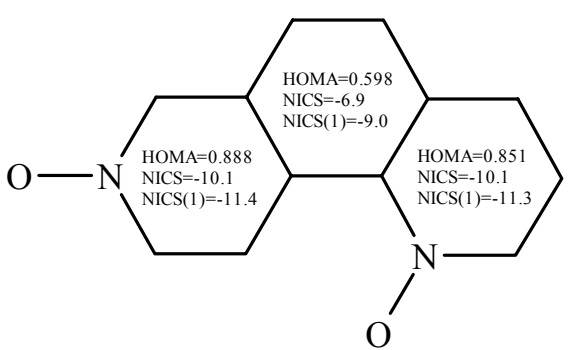

(c)

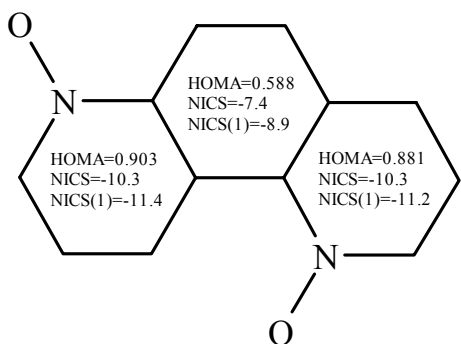

(b)

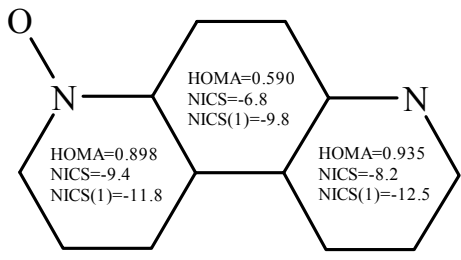

(d)

Figure 2. The local aromaticity of 1,7-phenanthroline 7-oxide (a), 1,7-phenanthroline 1,7dioxide (b), 1,8-phenanthroline 1,8-dioxide (c) and 4,7-phenanthroline 4-oxide (d). Based on experimental ${ }^{21}$ geometries.

In order to understand better the consequences of the substitution on $\pi$-electron structure of phenanthrene we have systematically analysed both global and local aromaticity of its $\mathrm{N}$ substituted and N,N-disubstituted derivatives and their N-oxides. Tables 1-2 present the local 
descriptors of $\pi$-electron delocalization: HOMA and NICS, and the global ones: the relative energy values (in respect to the lowest-energy isomer), the magnetic susceptibilities and the global values of HOMA (estimated for all bond lengths). Both relative energies and magnetic susceptibilities can serve only as approximate descriptors of aromaticity since they are always perturbed to some extent by additional effects ${ }^{23}$ such as strain, topological charge stabilization, ${ }^{24}$ heteroatom-heteroatom like anomeric effects, hyperconjugation and other effects which are not related to aromaticity. ${ }^{25}$

Table 1. Local (for the individual rings, HOMA, NICS and NICS(1) [ppm]) and global (Magnetic susceptibility $\chi$ [cgs-ppm], relative energy E [kcal/mol], and HOMA) descriptors of $\pi$ electron delocalization for aza-analogues of phenanthrene

\begin{tabular}{|c|c|c|c|c|c|c|c|}
\hline No. & Compound & Ring A & Ring B & Ring C & $\begin{array}{c}\text { Magnetic } \\
\text { susceptibil } \\
\text { ity } \\
\end{array}$ & E & $\begin{array}{l}\text { HOMA } \\
\text { (Global) }\end{array}$ \\
\hline \multirow[t]{3}{*}{1} & & $\mathrm{HOMA}=0.884$ & $\mathrm{HOMA}=0.507$ & $\mathrm{HOMA}=0.903$ & -126.4 & 0 & 0.771 \\
\hline & & $\mathrm{NICS}=-10.1$ & $\mathrm{NICS}=-6.4$ & $\mathrm{NICS}=-8.6$ & & & \\
\hline & & $\operatorname{NICS}(1)=-11.9$ & $\operatorname{NICS}(1)=-8.8$ & $\operatorname{NICS}()=-11.4$ & & & \\
\hline \multirow[t]{3}{*}{2} & & $\mathrm{HOMA}=0.875$ & $\mathrm{HOMA}=0.490$ & $\mathrm{HOMA}=0.895$ & -126.6 & 3.54 & 0.760 \\
\hline & & $\mathrm{NICS}=-10.3$ & $\mathrm{NICS}=-6.5$ & $\mathrm{NICS}=-8.8$ & & & \\
\hline & & $\operatorname{NICS}(1)=-11.9$ & $\operatorname{NICS}(1)=-8.9$ & $\operatorname{NICS}(1)=-11.5$ & & & \\
\hline \multirow[t]{3}{*}{3} & & $\mathrm{HOMA}=0.870$ & $\mathrm{HOMA}=0.499$ & $\mathrm{HOMA}=0.896$ & -127.4 & 3.13 & 0.762 \\
\hline & & $\mathrm{NICS}=-10.2$ & $\mathrm{NICS}=-6.6$ & $\mathrm{NICS}=-8.6$ & & & \\
\hline & & $\operatorname{NICS}(1)=-11.9$ & $\operatorname{NICS}(1)=-8.9$ & $\operatorname{NICS}(1)=-11.4$ & & & \\
\hline \multirow[t]{9}{*}{4} & & HOMA $=0.897$ & $\mathrm{HOMA}=0.482$ & $\mathrm{HOMA}=0.875$ & -126.4 & 1.99 & 0.761 \\
\hline & & $\mathrm{NICS}=-10.2$ & $\mathrm{NICS}=-6.5$ & $\mathrm{NICS}=-8.7$ & & & \\
\hline & & $\operatorname{NICS}(1)=-11.9$ & $\operatorname{NICS}(1)=-8.9$ & $\operatorname{NICS}(1)=-11.4$ & & & \\
\hline & & $\mathrm{HOMA}=0.882$ & $\mathrm{HOMA}=0.495$ & $\mathrm{HOMA}=0.893$ & & & \\
\hline & & $\mathrm{NICS}=-10.2$ & $\mathrm{NICS}=-6.5$ & $\mathrm{NICS}=-8.7$ & -126.7 & 2.05 & 0.764 \\
\hline & & $\operatorname{NICS}(1)=-11.9$ & $\operatorname{NICS}(1)=-8.9$ & $\operatorname{NICS}(1)=-11.4$ & & & \\
\hline & & $\mathrm{HOMA}=0.027$ & $\mathrm{HOMA}=0.025$ & $\mathrm{HOMA}=0.028$ & & & \\
\hline & Range for $1-4$ & $\mathrm{NICS}=0.8$ & $\mathrm{NICS}=0.2$ & $\mathrm{NICS}=-0.2$ & 0.8 & 3.54 & 0.011 \\
\hline & & $\operatorname{NICS}(1)=0.0$ & $\operatorname{NICS}(1)=0.1$ & $\operatorname{NICS}(1)=0.1$ & & & \\
\hline \multirow[t]{3}{*}{5} & & $\mathrm{HOMA}=0.883$ & $\mathrm{HOMA}=0.586$ & $\mathrm{HOMA}=0.898$ & -126.8 & 1.60 & 0.797 \\
\hline & & $\mathrm{NICS}=-10.9$ & $\mathrm{NICS}=-5.0$ & $\mathrm{NICS}=-10.2$ & & & \\
\hline & & $\operatorname{NICS}(1)=-11.8$ & $\operatorname{NICS}(1)=-8.5$ & $\operatorname{NICS}(1)=-11.9$ & & & \\
\hline
\end{tabular}


Table 2. Local (for the individual rings, HOMA, NICS and NICS(1) [ppm]) and global (Magnetic susceptibility $\chi$ [cgs-ppm], relative energy E [kcal/mol], and HOMA) descriptors of $\pi$ electron delocalization for $\mathrm{N}$-oxides of aza-analogues of phenanthrene

\begin{tabular}{|c|c|c|c|c|c|c|c|}
\hline No. & Compound & Ring A & Ring B & Ring C & $\begin{array}{c}\text { Magnetic } \\
\text { susceptibility }\end{array}$ & E & $\begin{array}{l}\text { HOMA } \\
\text { (Global) }\end{array}$ \\
\hline \multirow[t]{3}{*}{6} & & $\mathrm{HOMA}=0.838$ & $\mathrm{HOMA}=0.457$ & $\mathrm{HOMA}=0.749$ & -132.1 & 2.35 & 0.724 \\
\hline & & $\mathrm{NICS}=-11.0$ & $\mathrm{NICS}=-7.1$ & $\mathrm{NICS}=-10.6$ & & & \\
\hline & & $\operatorname{NICS}(1)=-12.5$ & $\operatorname{NICS}(1)=8.8$ & $\operatorname{NICS}(1)=-11.2$ & & & \\
\hline \multirow[t]{3}{*}{7} & & $\mathrm{HOMA}=0.870$ & HOMA $=0.509$ & $\mathrm{HOMA}=0.718$ & -131.2 & 1.58 & 0.747 \\
\hline & & $\mathrm{NICS}=-10.3$ & NICS $=-6.6$ & $\mathrm{NICS}=-9.8$ & & & \\
\hline & & $\operatorname{NICS}(1)=-12.0$ & $\operatorname{NICS}(1)=-8.9$ & $\operatorname{NICS}(1)=-10.6$ & & & \\
\hline \multirow[t]{3}{*}{8} & & $\mathrm{HOMA}=0.870$ & $\mathrm{HOMA}=0.509$ & $\mathrm{HOMA}=0.846$ & -131.7 & 1.57 & 0.749 \\
\hline & & $\mathrm{NICS}=-10.2$ & $\mathrm{NICS}=-6.5$ & $\mathrm{NICS}=-9.8$ & & & \\
\hline & & $\operatorname{NICS}(1)=-11.9$ & $\operatorname{NICS}(1)=-8.8$ & $\operatorname{NICS}(1)=-10.6$ & & & \\
\hline \multirow[t]{9}{*}{9} & & HOMA $=0.871$ & $\mathrm{HOMA}=0.553$ & $\mathrm{HOMA}=0.863$ & -132.6 & 0 & 0.765 \\
\hline & & $\mathrm{NICS}=-10.3$ & $\mathrm{NICS}=-7.5$ & $\mathrm{NICS}=-9.6$ & & & \\
\hline & & $\operatorname{NICS}(1)=-12.0$ & $\operatorname{NICS}(1)=-9.3$ & $\operatorname{NICS}(1)=-10.5$ & & & \\
\hline & & $\mathrm{HOMA}=0.868$ & $\mathrm{HOMA}=0.507$ & HOMA $=0.794$ & & & \\
\hline & Mean for 6-9 & $\mathrm{NICS}=-10.6$ & $\mathrm{NICS}=-6.9$ & $\mathrm{NICS}=-9.9$ & -131.9 & 1.42 & 0.757 \\
\hline & & $\operatorname{NICS}(1)=-12.1$ & $\operatorname{NICS}(1)=-9.0$ & $\operatorname{NICS}(1)=-10.7$ & & & \\
\hline & & HOMA $=0.052$ & HOMA $=0.097$ & $\mathrm{HOMA}=0.145$ & & & \\
\hline & Range for $6-9$ & $\mathrm{NICS}=-0.9$ & $\mathrm{NICS}=1.0$ & $\mathrm{NICS}=1.1$ & 1.4 & 2.35 & 0.039 \\
\hline & & $\operatorname{NICS}(1)=0.6$ & $\operatorname{NICS}(1)=0.6$ & $\operatorname{NICS}(1)=0.7$ & & & \\
\hline \multirow[t]{3}{*}{10} & & $\mathrm{HOMA}=0.890$ & $\mathrm{HOMA}=0.573$ & $\mathrm{HOMA}=0.927$ & -132.5 & -0.4 & 0.798 \\
\hline & & $\mathrm{NICS}=-11.1$ & $\mathrm{NICS}=-6.2$ & $\mathrm{NICS}=-9.9$ & & & \\
\hline & & $\operatorname{NICS}(1)=-12.1$ & $\operatorname{NICS}(1)=-7.8$ & $\operatorname{NICS}(1)=-11.5$ & & & \\
\hline
\end{tabular}

Neither the replacement of $\mathrm{CH}$ moiety by $\mathrm{N}$ atom, nor by $\mathrm{NO}$ group is associated with dramatic changes in the global descriptors of the $\pi$-electron delocalization. The global HOMA index reveals rather small variation in the range between 0.724 and 0.798 for 1-azaphenanthrene 1-oxide (6) and 9-azaphenanthrene 9-oxide (10), respectively. The lowest aromaticity in the former case is most probably caused by steric interactions between oxygen substituted at $\mathrm{N}_{1}$ and the $\mathrm{CH}$ fragment in position 10. Both in the case of aza-derivatives and the N-oxides the HOMA values are remarkable higher (HOMA $=0.764$ and 0.757 , respectively) than for phenanthrene system $(\mathrm{HOMA}=0.741)$, suggesting more effictive $\pi$-electron delocalization, especially in the case of aza-derivatives. Also the other descriptors (the relative energy, the magnetic susceptibility and HOMA) confirm that the changes within the isomeric groups are very small. Interestingly to note that the changes in energy in a series of aza-derivatives are somewhat 
greater $(3.54 \mathrm{kcal} / \mathrm{mole})$ than for their $\mathrm{N}$-oxides $(2.35 \mathrm{kcal} / \mathrm{mole})$. Thus, it may be expected that the N-oxidation causes less specific changes in the phenanthrene structure. A deeper insight may be obtained by looking at the descriptors of the $\pi$-electron delocalization for individual rings. The bond length alternation indicates, that the terminal rings are more aromatic than the central fragment. Moreover, the former rings are more aromatic in phenanthrolines than in the N-oxides while for the latter fragment it is reversed. Surprisely, both NICS and NICS(1) are more negative for the rings in the N-oxides, and moreover, they are only slightly less negative (within $1 \mathrm{ppm}$ ) than for phenanthrene. This shows that consequences of the cyclic $\pi$-electron delocalization are somewhat different for the geometry pattern and magnetic properties, what indicates a multidimensional character ${ }^{15 \mathrm{e}}$ of aromaticity descriptors. Despite of this, it is important to note that the extent of changes is very small, and approaches well the structure of phenanthrene.

Tables 3-5 present the global and local descriptors of $\pi$-electron delocalization for di-azaanalogues of phenanthrene and their N-oxides and N,N-dioxides. The global descriptors, the values of energy and magnetic susceptibility in the series of diaza-analogues and of their $\mathrm{N}$ oxides alike as for mono-analogues may be directly compared.

Table 3. Local (for the individual rings, HOMA, NICS and NICS(1) [ppm]) and global (Magnetic susceptibility $\chi$ [cgs-ppm], relative energy E [kcal/mol], and HOMA) descriptors of $\pi$ electron delocalization for diaza analogues of phenanthrene

\begin{tabular}{|c|c|c|c|c|c|c|c|}
\hline No & Compound & Ring A & Ring B & Ring C & $\begin{array}{c}\text { Magnetic } \\
\text { susceptibility } \\
\end{array}$ & $\mathrm{E}$ & $\begin{array}{l}\text { HOMA } \\
\text { (Global) } \\
\end{array}$ \\
\hline \multirow[t]{3}{*}{11} & & HOMA $=0.911$ & $\mathrm{HOMA}=0.533$ & HOMA $=0.906$ & -119.9 & 0 & 0.789 \\
\hline & & $\mathrm{NICS}=-8.5$ & $\mathrm{NICS}=-6.5$ & $\mathrm{NICS}=-8.6$ & & & \\
\hline & & $\operatorname{NICS}(1)=11.4$ & $\operatorname{NICS}(1)=-8.9$ & $\operatorname{NICS}(1)=-11.4$ & & & \\
\hline \multirow[t]{3}{*}{12} & & $\mathrm{HOMA}=0.909$ & $\mathrm{HOMA}=0.537$ & $\mathrm{HOMA}=0.905$ & -121.1 & 1.92 & 0.787 \\
\hline & & $\mathrm{NICS}=-8.8$ & $\mathrm{NICS}=-6.6$ & $\mathrm{NICS}=-8.7$ & & & \\
\hline & & $\operatorname{NICS}(1)=-11.6$ & $\operatorname{NICS}(1)=-8.9$ & $\operatorname{NICS}(1)=11.6$ & & & \\
\hline \multirow[t]{3}{*}{13} & & $\mathrm{HOMA}=0.907$ & $\mathrm{HOMA}=0.535$ & $\mathrm{HOMA}=0.903$ & -119.9 & 2.36 & 0.787 \\
\hline & & $\mathrm{NICS}=-8.6$ & $\mathrm{NICS}=-6.5$ & $\mathrm{NICS}=-8.5$ & & & \\
\hline & & $\operatorname{NICS}(1)=-11.4$ & $\operatorname{NICS}(1)=-8.9$ & $\operatorname{NICS}(1)=-11.4$ & & & \\
\hline \multirow[t]{3}{*}{14} & & $\mathrm{HOMA}=0.894$ & $\mathrm{HOMA}=0.469$ & HOMA $=0.894$ & -120.2 & 5.27 & 0.762 \\
\hline & & $\mathrm{NICS}=-8.8$ & $\mathrm{NICS}=-6.5$ & $\mathrm{NICS}=-8.8$ & & & \\
\hline & & $\operatorname{NICS}(1)=-11.6$ & $\operatorname{NICS}(1)=-8.9$ & $\operatorname{NICS}(1)=-11.6$ & & & \\
\hline \multirow[t]{3}{*}{15} & & HOMA $=0.899$ & $\mathrm{HOMA}=0.516$ & HOMA $=0.899$ & -120.4 & 5.86 & 0.774 \\
\hline & & $\mathrm{NICS}=-8.9$ & $\mathrm{NICS}=-6.5$ & $\mathrm{NICS}=-8.9$ & & & \\
\hline & & $\operatorname{NICS}(1)=-11.6$ & $\operatorname{NICS}(1)=-8.9$ & $\operatorname{NICS}(1)=-11.6$ & & & \\
\hline \multirow[t]{3}{*}{16} & & HOMA $=0.905$ & $\mathrm{HOMA}=0.534$ & HOMA $=0.901$ & -120.8 & 5.24 & 0.779 \\
\hline & & $\mathrm{NICS}=-8.6$ & $\mathrm{NICS}=-6.5$ & $\mathrm{NICS}=-8.7$ & & & \\
\hline & & $\operatorname{NICS}(1)=-11.4$ & $\operatorname{NICS}(1)=-8.8$ & $\operatorname{NICS}(1)=-11.5$ & & & \\
\hline
\end{tabular}


Table 3. Continued

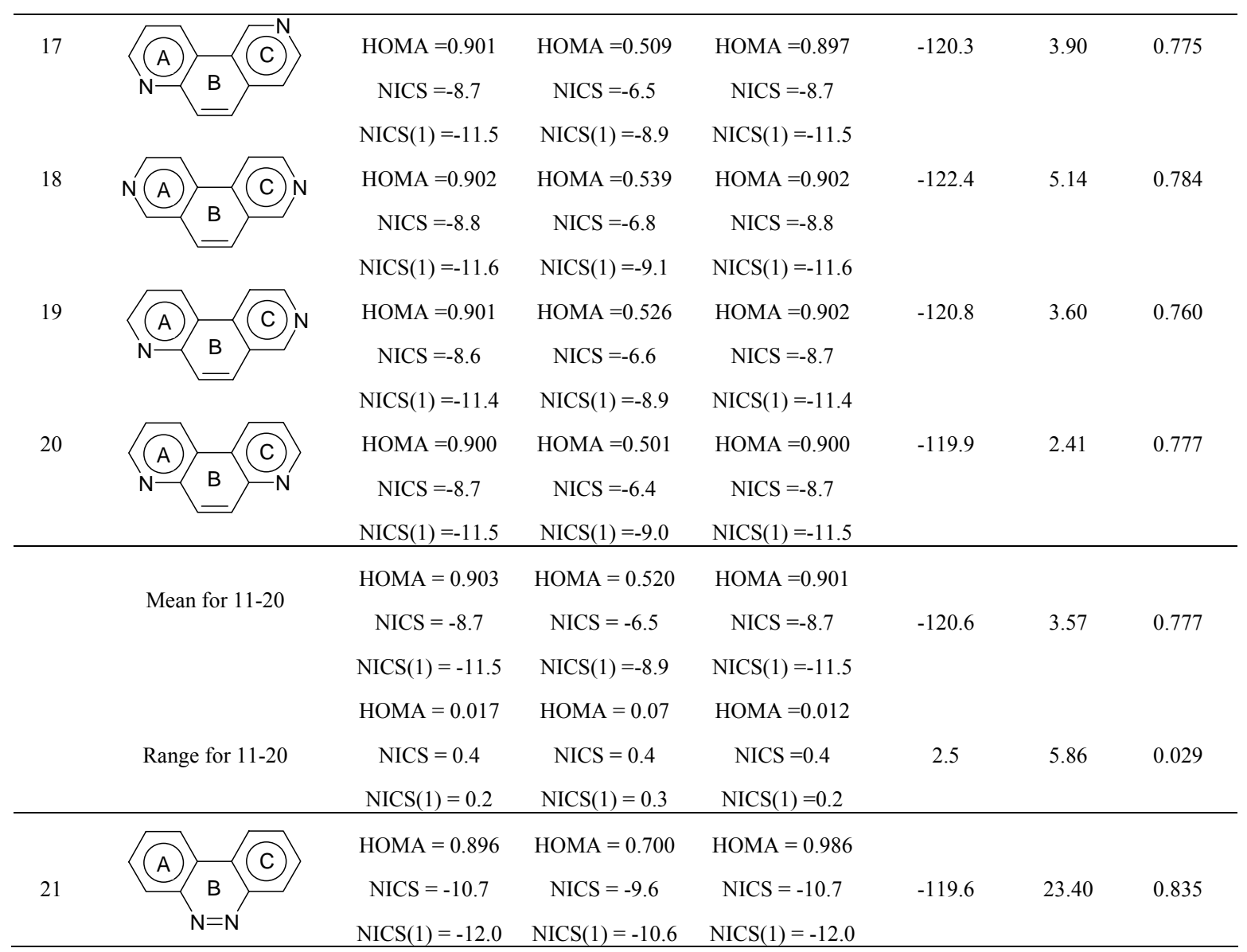

Table 4. Local (for the individual rings, HOMA, NICS and NICS(1) [ppm]) and global (Magnetic susceptibility $\chi$ [cgs-ppm], relative energy $\mathrm{E}[\mathrm{kcal} / \mathrm{mol}]$, and HOMA) descriptors of $\pi$ electron delocalization for mono $\mathrm{N}$-oxides of diaza analogues of phenanthrene

\begin{tabular}{|c|c|c|c|c|c|c|c|}
\hline No & Compound & Ring A & Ring B & Ring C & $\begin{array}{c}\text { Magnetic } \\
\text { susceptibility }\end{array}$ & E & $\begin{array}{l}\text { HOMA } \\
\text { (Global) }\end{array}$ \\
\hline \multirow[t]{3}{*}{22} & & $\mathrm{HOMA}=0.866$ & $\mathrm{HOMA}=0.485$ & $\mathrm{HOMA}=0.844$ & -125.8 & 3.4 & 0.746 \\
\hline & & $\mathrm{NICS}=-9.2$ & $\mathrm{NICS}=-7.3$ & $\mathrm{NICS}=-10.8$ & & & \\
\hline & & $\operatorname{NICS}(1)=-11.9$ & $\operatorname{NICS}(1)=-8.9$ & $\operatorname{NICS}(1)=-11.3$ & & & \\
\hline \multirow[t]{3}{*}{23} & & $\mathrm{HOMA}=0.902$ & $\mathrm{HOMA}=0.588$ & $\mathrm{HOMA}=0.879$ & -126.3 & 0 & 0.789 \\
\hline & & $\mathrm{NICS}=-8.7$ & $\mathrm{NICS}=-7.5$ & $\mathrm{NICS}=-9.6$ & & & \\
\hline & & $\operatorname{NICS}(1)=-11.6$ & $\operatorname{NICS}(1)=-9.3$ & $\operatorname{NICS}(1)=-10.6$ & & & \\
\hline \multirow[t]{3}{*}{24} & & $\mathrm{HOMA}=0.879$ & $\mathrm{HOMA}=0.510$ & $\mathrm{HOMA}=0.846$ & -126.3 & 3.8 & 0.753 \\
\hline & & $\mathrm{NICS}=-9.5$ & $\mathrm{NICS}=-7.3$ & $\mathrm{NICS}=-10.5$ & & & \\
\hline & & $\operatorname{NICS}(1)=-12.2$ & $\operatorname{NICS}(1)=-8.9$ & $\operatorname{NICS}(1)=-11.1$ & & & \\
\hline
\end{tabular}


Table 4. Continued

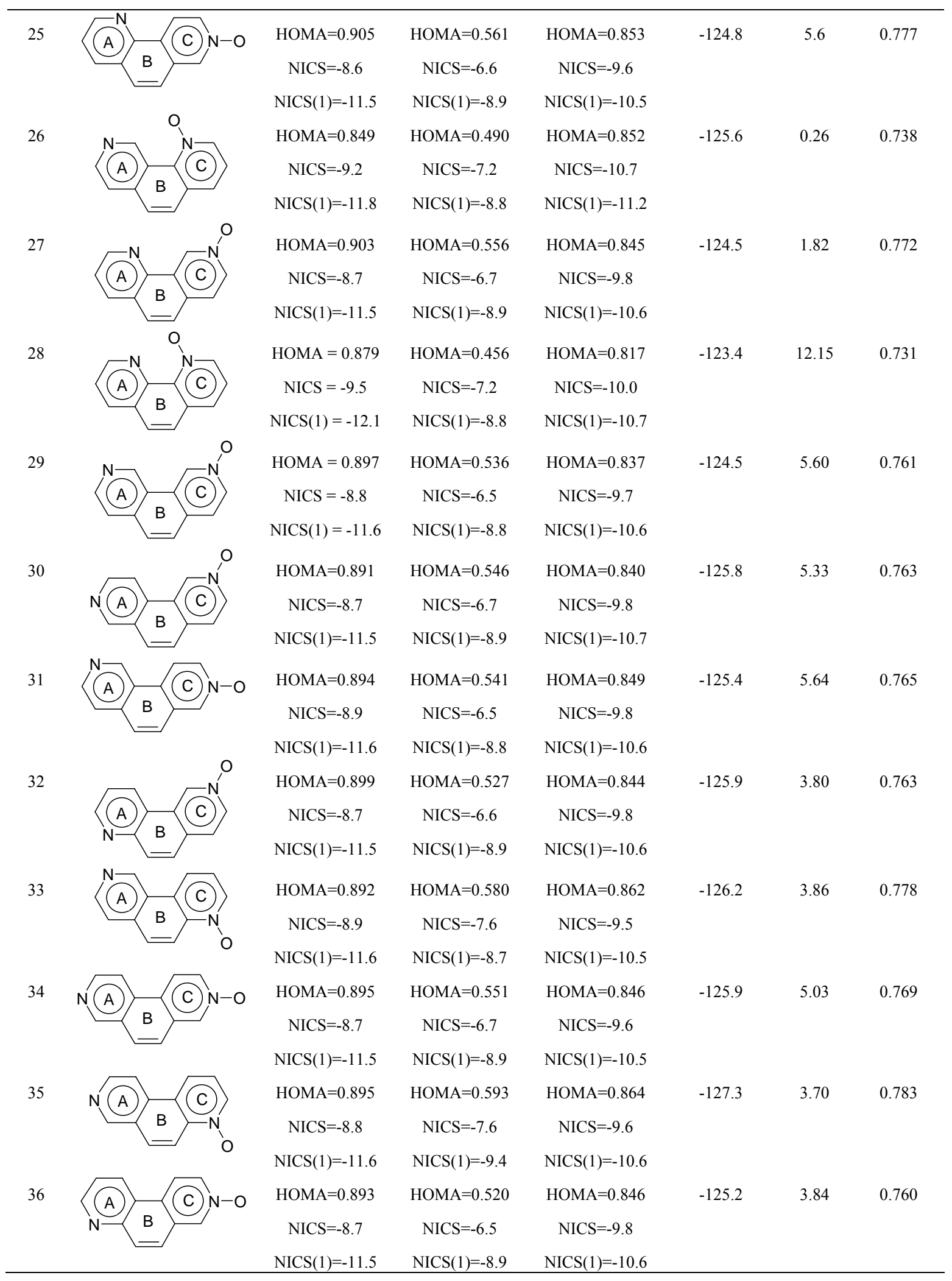


Table 4. Continued

$\begin{array}{cccccc}\text { HOMA }=0.894 & \mathrm{HOMA}=0.575 & \mathrm{HOMA}=0.864 \\ \mathrm{NICS}=-7.5 & -125.9 & 2.38 & 0.780 \\ \mathrm{NICS}=-9.6 & & \\ \mathrm{NICS}(1)=-10.5 \\ \end{array}$

Table 5. Local (for the individual rings, HOMA, NICS and NICS(1) [ppm]) and global (magnetic susceptibility $\chi$ [cgs-ppm], relative energy E [kcal/mol], and HOMA) descriptors of $\pi$ electron delocalization for $\mathrm{N}, \mathrm{N}$ - dioxides of diaza analogues of phenanthrene

\begin{tabular}{|c|c|c|c|c|c|c|c|}
\hline No & Compound & Ring A & Ring B & Ring C & $\begin{array}{c}\text { Magnetic } \\
\text { susceptibility }\end{array}$ & E & $\begin{array}{l}\text { HOMA } \\
\text { (Global) }\end{array}$ \\
\hline \multirow[t]{3}{*}{39} & & $\mathrm{HOMA}=0.835$ & $\mathrm{HOMA}=0.549$ & $\mathrm{HOMA}=0.836$ & -132.3 & 1.65 & 0.747 \\
\hline & & $\mathrm{NICS}=-10.5$ & $\mathrm{NICS}=-8.1$ & $\mathrm{NICS}=-10.7$ & & & \\
\hline & & $\operatorname{NICS}(1)=-11.2$ & $\operatorname{NICS}(1)=-9.3$ & $\operatorname{NICS}(1)=-11.3$ & & & \\
\hline \multirow[t]{3}{*}{40} & & $\mathrm{HOMA}=0.815$ & HOMA $=0.519$ & $\mathrm{HOMA}=0.846$ & -130.2 & 2.03 & 0.738 \\
\hline & & $\mathrm{NICS}=-10.3$ & $\mathrm{NICS}=-7.2$ & $\mathrm{NICS}=-10.6$ & & & \\
\hline & & $\operatorname{NICS}(1)=-11.1$ & $\operatorname{NICS}(1)=-8.8$ & $\operatorname{NICS}(1)=-11.2$ & & & \\
\hline \multirow[t]{3}{*}{41} & & $\mathrm{HOMA}=0.811$ & $\mathrm{HOMA}=0.534$ & HOMA $=0.844$ & -129.6 & 3.17 & 0.734 \\
\hline & & $\mathrm{NICS}=-10.6$ & $\mathrm{NICS}=-7.3$ & $\mathrm{NICS}=-10.6$ & & & \\
\hline & & $\operatorname{NICS}(1)=-11.2$ & $\operatorname{NICS}(1)=-8.8$ & $\operatorname{NICS}(1)=-11.2$ & & & \\
\hline \multirow[t]{3}{*}{42} & & $\mathrm{HOMA}=0.856$ & HOMA $=0.569$ & $\mathrm{HOMA}=0.856$ & -127.0 & 15.87 & 0.765 \\
\hline & & $\mathrm{NICS}=-9.9$ & $\mathrm{NICS}=-6.1$ & $\mathrm{NICS}=-9.9$ & & & \\
\hline & & $\operatorname{NICS}(1)=-10.4$ & $\operatorname{NICS}(1)=-7.6$ & $\operatorname{NICS}(1)=-10.4$ & & & \\
\hline \multirow[t]{3}{*}{43} & & $\mathrm{HOMA}=0.837$ & $\mathrm{HOMA}=0.549$ & $\mathrm{HOMA}=0.837$ & -128.8 & 3.21 & 0.746 \\
\hline & & $\mathrm{NICS}=-9.8$ & NICS $=-6.7$ & $\mathrm{NICS}=-9.8$ & & & \\
\hline & & $\operatorname{NICS}(1)=-10.6$ & $\operatorname{NICS}(1)=-8.9$ & $\operatorname{NICS}(1)=-10.6$ & & & \\
\hline \multirow[t]{3}{*}{44} & & $\mathrm{HOMA}=0.846$ & $\mathrm{HOMA}=0.551$ & $\mathrm{HOMA}=0.837$ & -129.7 & 2.84 & 0.750 \\
\hline & & $\mathrm{NICS}=-9.8$ & $\mathrm{NICS}=-6.7$ & $\mathrm{NICS}=-9.8$ & & & \\
\hline & & $\operatorname{NICS}(1)=-10.6$ & $\operatorname{NICS}(1)=-8.9$ & $\operatorname{NICS}(1)=-10.6$ & & & \\
\hline
\end{tabular}


Table 5. Continued

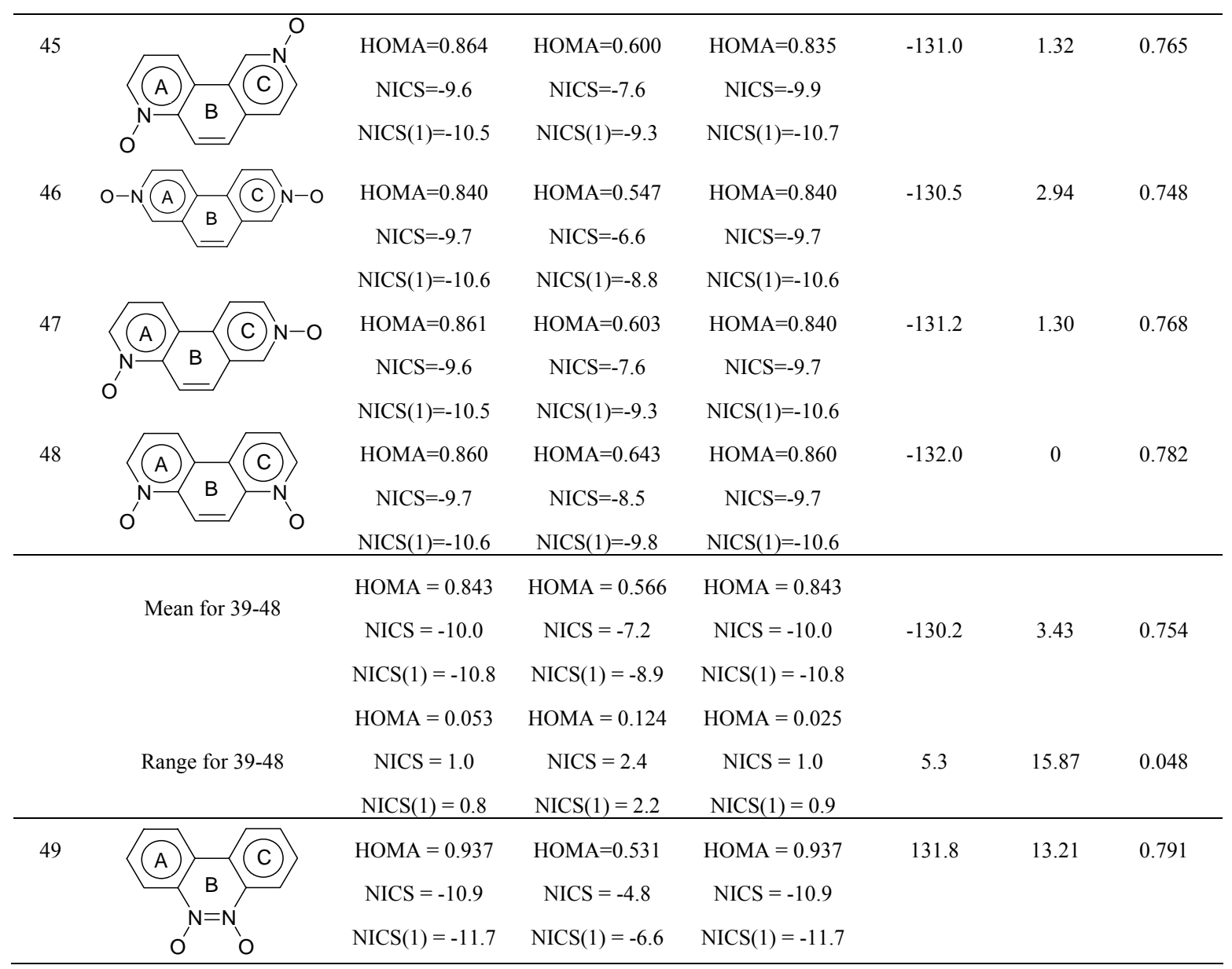

Similarly as in the case of aza-analogues of phenanthrene the global parameters (HOMA, relative energy (E) and magnetic susceptibility) for ten isomers of diaza analogues do not vary too much. The mean value of the relative energy equals to $3.57 \mathrm{kcal} / \mathrm{mole}$ and the range of its variation equals to $5.9 \mathrm{kcal} / \mathrm{mole}$. It still indicates a rather small perturbation of the extent of $\pi$ electron delocalization, but the changes are appreciably higher than for monoaza-analogues. These findings are in line with small ranges of other descriptors: HOMA and the magnetic susceptibility. It is important to note that the global HOMA is always greater than for phenanthrene which indicates a slight increase of the $\pi$-electron delocalization. This tendency is well reflected in local aromaticities: both terminal rings in aza-analogues exhibit a substantial increase of $\pi$-electron delocalization (with the mean HOMA values greater than 0.90 ) and for the central ring the effect is even stronger (the mean HOMA is 0.52). Again the most perturbed system is 1,10-phenanthroline (14), where the steric effects of nitrogen atom lone pairs may interfere, leading to significant decrease of the $\pi$-electron delocalisation. In turn, the 9,10diazaphenanthrene system (21) is the most aromatic in the series as pointed by large HOMA value and highly negative NICS(1). For instance the former is equal to 0.70 and the later is equal to $-10.6 \mathrm{ppm}$ for the central ring of the system, while for phenanthrene it equals to 0.46 and -9.6 , 
respectively. Despite of this the system is much less stable (by $23.4 \mathrm{kcal} / \mathrm{mol}$ ) than the lowest energy isomer (1,7-phenanthroline, 11), due to strong nitrogen-nitrogen interactions, which is not related to aromaticity. ${ }^{23}$

The N-oxidation leads only to a moderate decreases of the extent of the $\pi$-electron delocalization (the mean total HOMA is 0.764), but still it is often higher than for the phenanthrene parent system. Consequently, the ranges of the variation of the relative energy and magnetic susceptibility are significantly higher, whereas the 1,10-phenanthroline 1-oxide (28) exhibit the smallest $(\mathrm{HOMA}=0.731)$ and the 9,10-diazaphenanthrene 9-oxide (38) the highest $(\mathrm{HOMA}=0.813)$ extent of electron delocalization in the set. The analysis for individual rings is somewhat unexpected. From one side the central ring exhibit an increase of $\pi$-electron delocalization (mean HOMA $=0.538$ ) as compared with diaza phenanthrenes (mean $\mathrm{HOMA}=0.520$ ) while for both terminal rings the delocalization is less efficient (mean $\mathrm{HOMA}=0.890$ for ring containing nitrogen atom, and mean $\mathrm{HOMA}=0.849$ for ring containing NO group). Clearly the $\mathrm{N}$-oxidation decrease the extent $\pi$-electron delocalization.

In the case of N,N-dioxides an additional lowering of aromaticity is observed. The mean HOMA value is slightly lower (0.754) than for diazaphenanthrene N-oxides and parent diazaphenanthrenes, and it is very similar to that observed for phenanthrene. As expected, the ranges of variation of energy and magnetic susceptibility are much greater than in the former cases. The local indications of the $\pi$-electron delocalization shows that both terminal rings are less aromatic (mean $\mathrm{HOMA}=0.843$ and $\mathrm{NICS}(1)=-10.8$ ) than the respective rings in diaazaphenanthrene $\mathrm{N}$-oxides and diaza analogues (mean HOMA $=0.890$ and 0.903 ; mean NICS $=-11.7$ and -11.5 , respectively). However, in the case of the central ring it is opposite: the HOMA indicates an increase of aromaticity (mean HOMA $=0.566$ for this group and mean HOMA $=0.538$ and 0.520 for former groups, respectively) while NICS shows a decrease of the $\pi$ electron delocalization (mean $\operatorname{NICS}(1)=-8.9$ for this group and $\operatorname{NICS}(1)=-9.0$ and -8.9 for former cases, respectively). In the case when the central ring contains $\mathrm{N}-\mathrm{O}$ groups a simultaneous decrease of cyclic $\pi$-electron delocalisation is observed: HOMA $=0.531$ and $\operatorname{NICS}(1)=-6.6$ for the N,N-dioxides, and HOMA $=0.608$ and 0.700 while $\operatorname{NICS}(1)=-6.9$ and -10.6 for diazaphenanthrene $\mathrm{N}$-oxides and diaza analogues, respectively. It may be concluded that the presence of the nitrogen atom or N-O group lead to more efficient delocalization in neighboring fragment(s). The replacement of the $\mathrm{CH}$ group by nitrogen(s) usually makes the cyclic $\pi$-electron delocalization of a fragment more efficient, while the oxidation leads to decrease of aromaticity of this fragment.

\section{Conclusions}

Despite of the substantial perturbations of phenanthrene moiety by the replacement of one or two $\mathrm{CH}$ units by nitrogen atom and/or $\mathrm{N}$-oxide groups, the $\pi$-electron delocalization is usually changed only moderately. The aza-analogues usually exhibit more effective $\pi$-electron 
delocalization, while the N-oxidation leads to its small decrease. The outer rings are always more aromatic than the central rings. This finding is in line with the view ${ }^{17 b, d}$ that the topological requirements of the connectivity of rings in benzenoid hydrocarbons is decisive for the global (for the whole molecule) and local (i.e. for individual rings) $\pi$-electron delocalisation. Usually the lowering of delocalization in an N-oxidized fragment imply a substantial increase of aromaticity of neighboring rings. The central rings of the aza-, diaza- and their N-oxides are often more aromatic than in phenanthrene. Often there is no detailed agreement between quantitative descriptors of aromatic character. Consequently, the aromaticity of monoaza, diazaphenanthrenes analogues and their $\mathrm{N}$-oxides can be regarded as statistically multidimensional. ${ }^{15 \mathrm{e}}$

\section{Computational and Experimental Section}

Materials. Phenanthroline $N$-oxide (a-d) were synthetized by oxidation of parent phenanthrolines as described in reference. ${ }^{26}$

X-ray. The X-ray measurements of 1,7-phenanthroline 7-oxide (a), 1,7-phenanthroline 1,7dioxide (b), 1,8-phenanthroline 1,8-dioxide (c) and 4,7-phenanthroline 4-oxide (d) (see Fig. 1) were performed at low temperature (at $100.0 \pm 0.1 \mathrm{~K}$ ) on a KUMA CCD k-axis diffractometer with graphite-monochromatized Mo Ka radiation $(0.71073 \AA)$. The crystals were positioned at $62.2 \mathrm{~mm}$ from the KM4CCD camera. 796 frames were measured at 1.600 intervals on a counting time of 25, 20, 15, 30 for the crystals of (a), (b), (c), (d), respectively. Data reductions and analysis were caried out with the Kuma Diffraction programs (Wrocław, Poland). The data were corrected for Lorentz and polarization effects, but no absorption correction was applied. The structure were solved by direct methods ${ }^{27}$ and refined using SHELXL. ${ }^{28}$ The refinement was based on $\mathrm{F}^{2}$ for all reflections except those with very negative $\mathrm{F}^{2}$. The weighted $\mathrm{R}$ factors wR and all goodness-of-fit $\mathrm{S}$ values are based on $\mathrm{F}^{2}$. The non-hydrogen atoms were refined anisotropically, whereas the hydrogen atoms were located from a differential map and refined isotropically. Scattering factors were taken from International Tables for X-ray crystallography. ${ }^{29}$ Table 6 presents the selected crystal data and structure refinement. Crystallographic data for the structures have been deposisited with the Cambridge Structural Database Center as supplementary publication No. CCDC 213188 (a), CCDC 213189 (b), CCDC 213190 (c) and CCDC 213191 (d). Copies of the data can be obtained on application to CCDC, 12 Union Road, Cambridge CB2 1 EZ, UK (e-mail: deposit@ccdc.cam.ac.uk).

Calculations. The geometries were computed with the GAUSSIAN 98 program $^{20}$ at the B3LYP/6-311G** level of theory. All species corresponded to minima at the B3LYP/6-311G** level, with no imaginary frequencies. The CSGT/HF/6-311G** method was used for the calculations of magnetic susceptibilities and $\mathrm{GIAO} / \mathrm{HF} / 6-31+\mathrm{G}^{*}$ for NICS. The NICS were calculated both at ring center and $1 \AA$ above the molecular planes. The HOMA values based on molecular geometries optimized at the B3LYP/6-311G** level. 
Table 6. Selected crystal data and structure refinement for 1,7-phenanthroline 7oxide (a), 1,7phenanthroline 1,7-dioxide (b) 1,8-phenanthroline 1,8-dioxide (c) and 4,7-phenanthroline 4-oxide

\begin{tabular}{|c|c|c|c|c|}
\hline Compound & (a) & (b) & (c) & (d) \\
\hline Empirical formula & $\mathrm{C}_{12} \mathrm{H}_{8} \mathrm{~N}_{2} \mathrm{O}_{1} \times 2 \mathrm{H}_{2} \mathrm{O}$ & $\mathrm{C}_{12} \mathrm{H}_{8} \mathrm{~N}_{2} \mathrm{O}_{2} \times 2 \mathrm{H}_{2} \mathrm{O}$ & $\mathrm{C}_{12} \mathrm{H}_{8} \mathrm{~N}_{2} \mathrm{O}_{2} \times \mathrm{H}_{2} \mathrm{O}$ & $\mathrm{C}_{12} \mathrm{H}_{8} \mathrm{~N}_{2} \mathrm{O}_{1} \times 2 \mathrm{H}_{2} \mathrm{O}$ \\
\hline Crystal system & Orthorhombic & Orthorhombic & Monoclinic & Triclinic \\
\hline Space group & Pbca & Pbca & $\mathrm{P} 22_{1} / \mathrm{n}$ & P-1 \\
\hline \multicolumn{5}{|l|}{ Unit cell dimensions: } \\
\hline $\mathrm{a}[\AA]$ & $6.721(1)$ & $6.645(1)$ & $12.257(3)$ & $6.647(1)$ \\
\hline $\mathrm{b}[\AA]$ & $13.676(3)$ & $14.424(3)$ & $6.767(1)$ & $9.190(2)$ \\
\hline $\mathrm{c}[\AA]$ & $23.337(5)$ & $22.735(5)$ & $12.932(3)$ & $9.210(2)$ \\
\hline$\alpha\left[^{0}\right]$ & 90 & 90 & 90 & $87.31(3)$ \\
\hline$\beta\left[^{\circ}\right]$ & 90 & 90 & $110.60(3)$ & $87.11(3)$ \\
\hline$\gamma\left[{ }^{\circ}\right]$ & 90 & 90 & 90 & $73.67(3)$ \\
\hline Volume $\left[\AA^{3}\right]$ & $2145.1(7)$ & $2178.9(7)$ & $1004.0(4)$ & $2538.9(2)$ \\
\hline Z & 8 & 8 & 4 & 2 \\
\hline $\begin{array}{c}\text { Absorption coefficient } \\
{\left[\mathrm{mm}^{-1}\right]}\end{array}$ & 0.105 & 0.116 & 0.112 & 0.105 \\
\hline Reflection collected & 21697 & 21927 & 10545 & 5680 \\
\hline Final R [I>2sigma(I)] & $\begin{aligned} \mathrm{R} & =0.0372 \\
\mathrm{wR}^{2} & =0.0957\end{aligned}$ & $\begin{array}{c}\mathrm{R}=0.0482, \\
\mathrm{wR}^{2}=0.1116\end{array}$ & $\begin{array}{c}\mathrm{R}=0.0583 \\
\mathrm{wR}^{2}=0.1328\end{array}$ & $\begin{aligned} \mathrm{R} & =0.0432 \\
\mathrm{wR}^{2} & =0.1094\end{aligned}$ \\
\hline
\end{tabular}

\section{Supporting Information Available}

The Cartesian coordinates, absolute electronic energies at B3LYP/6-311G** and zero-point vibrational energies ZPE at B3LYP/6-311G** for all analysed aza-analogues of phenanthrene and its N-oxides and N,N-dioxides. Crystal data, structure refinement parameters and ORTEP view of molecule $\mathbf{a}, \mathbf{b}, \mathbf{c}$, and $\mathbf{d}$.

\section{Acknowledgments}

B. T. S. acknowledges the Interdisciplinary Center for Mathematical and Computational Modelling (Warsaw University) for computational facilities. The KBN 1407/T09/2001/21 grant provided financial support for this study. Mr Krystian Kloc is gratefully acknowledged for supply of phenanthroline N-oxides. 


\section{References and Notes}

1. Newkome, G. R.; Theriot, K. J.; Gupta, V. G.; Fronczek, F. R.; Baker, G. R. J. Org. Chem. 1989, 54, 1766.

2. (a) Shulman, A.; Dwyer, F. P.; In Chelating Agents and Metal Chelates; Dwyer F. P., Mellor, D. P., Eds; Academic Press: New York, 1964; p 383. (b) Mohindru, A.; Fisher, J. M.; Rabinovitz, M. Biochem. Pharm. 1983, 32, 3627. (c) Vasil'eva, S. V.; Stupakova, M. V.; Lobysheva, I. I.; Mikoyan, V. D.; Vanin, A. F. Biochem. (Moscow) 2001, 66, 984. (d) Yapi, A. D.; Mustofa, M.; Valentin, A.; Chavignon, O.; Teulade, J. C.; Mallie, M.; Chapat, J. P.; Blache, Y. Chem. Pharm. Bull. 2000, 48, 1886. (e) Geraghty, M.; McCann, M.; Devereux, M.; McKee, V. Inorg. Chim. Acta 1999, 293, 160. (f) Shen, X.; Kang, B.S.; Tong, Y. X.; Shi, X. F.; Li, Y. M.; Huang, X. Y. J. Coord. Chem. 1998, 46, 105. (g) Lin, J. Y.; Ma, D. J.; Zhong, W. Y. J. Rare Earth 1997, 15, 95. (h) Enan, E.; Lasley, B.; Stewart, D.; Overstreet, J.; Vandevoort, C. A. Reprod. Toxicol. 1996, 10, 191. (i) Mabrouk, H. E.; ElAsmy, A. A.; Khalifa, M. I.; Zedan, M. Syn. React. Ingorg. Met. 1996, 26, 423. (j) Ito, Y.; Pagano, P. J.; Tornheim, K.; Brecher, P.; Cohen, R. A. Am. J. Physiol.-Heart. C. 1996, 39, 81.

3. (a) Gillard, R. D. Coord. Chem. Rev. 1975, 16, 67. (b) Karayannis, N. M.; Speca, A. N.; Chasan, D. E.; Pytlewski, L. L. Coord. Chem. Rev. 1976, 20, 37.; (c) Engbersen, J. F. J.; Koudijs, A.; Joosten, M. H. A.; van der Plas, H. C. J. Heterocycl. Chem. 1986, 23, 989.

4. (a) Chandler, C. J.; Deady, L. W.; Reiss, J. A.; Tzimos, J. J. Heterocycl. Chem. 1982, 19, 1017. (b) Dietrich-Buchecker, C.; Saad, Z.; Sauvage, J.-P. J. Am. Chem. Soc. 1988, 110, 1467.

5. (a) Beauchamp, D. A.; Loeb, S. J. Chemistry Eur. J. 2002, 8, 5084. (b) Kurth, D. G.; Fromm, K. M.; Lehn, J. M. Eur. J. Inorg. Chem. 2001, 6, 1523. (c) Chu, D. Q.; Xu, J. Q.; Duan, L. M.; Wang, T. G.; Tang, A. Q.; Ye, L. Eur. J. Inorg. Chem. 2001, 5, 1135. (d) Russell, V.; Scudder, M.; Dance, I.; J. Chem. Soc. Dalton Trans. 2001, 6, 789. (e) Ferguson, G., Glidewell, C.; Lavender, E. S. Acta Cryst. B. 1999, 55, 591.

6. Rozen, S.; Dayan, S. Angew. Chem., Int. Ed. 1999, 38, 3472.

7. (a) Clar, E., The Aromatic Sextet; Wiley: New York, 1972; (b) Clar, E. Polycyclic Hydrocarbons; Academic Press: London and New York, 1964.

8. Schroeder, G. Ber. 1924, 57, 2003, 2015.

9. (a) Kruszewski, J.; Krygowski, T. M. Tetrahedron Let. 1972, 3842. (b) Krygowski, T. M. J. Chem. Inf. Comput. Sci. 1993, 33, 70. The HOMA is defined as follows: HOMA $=1-\frac{\alpha}{\mathrm{n}} \sum\left(\mathrm{d}_{\mathrm{opt}}-\mathrm{d}_{\mathrm{i}}\right)^{2}$, where $\mathrm{n}$ is the number of bonds taken into account; $\alpha$ (equal to 257.7 and 93.52 for $\mathrm{CC}$ and $\mathrm{CN}$ bonds, respectively) is a normalisation constant (to give $\mathrm{HOMA}=0$ for a model nonaromatic system and $\mathrm{HOMA}=1$ for the system with all bonds equal to the optimal value) $\mathrm{d}_{\mathrm{opt}}$ - optimal bond length which is assumed to be realised when full delocalization of $\pi$ electrons occurs (1.388 $\AA$ and $1.334 \AA$ for $\mathrm{CC}$ and $\mathrm{CN}$ bonds, respectively); $\mathrm{d}_{\mathrm{i}}$ are the experimental/computed bond lengths. 
10. Schleyer, P. v. R.; Mearker, C.; Dransfeld, A; Jiao, H. J. Am. Chem. Soc. 1996, 118, 6317.

11. Schleyer, P.v.R. Chem. Rev. 2001, 101, 1115.

12. Cyrański, M. K.; Stępień, B. T.; Krygowski, T. M. Tetrahedron 2000, 56, 9663.

13. Schleyer, P. v. R.; Manoharan, M.; Wang, Z.; Kiran, B.; Jiao, H.; Puchta, R.; Hommes, N. J. R. v. E., Org. Lett. 2001, 3, 2465.

14. Cyrański, M., Krygowski, T.M., Tetrahedron 1996, 52, 1713.

15. (a) Krygowski, T. M.; Cyrański, M. K. Chem. Rev. 2001, 105, 1385. (b) Krygowski, T. M.; Cyrański, M. K.; Czarnocki, Z.; Häfelinger, G.; Katritzky, A. R. Tetrahedron 2000, 56, 1783. (c) Krygowski, T. M.; Cyrañski, M. In Advances in Molecular Structure Research; Hargittai, I., Hargittai, M., Eds.; JAI Press: 1997; Vol. 3, p 227. (d) Cyrañski, M. K.; Krygowski, T. M.; Wisiorowski, M.; Hommes, v. E. N. J. R. Angew. Chem., Int. Ed. 1998, 37, 177. (e) Cyrański, M. K.; Krygowski, T. M.; Katritzky, A. R.; Schleyer, P. v. R. J. Org. Chem. 2002, 67, 1333.

16. Howard, S.T., Krygowski, T. M. Can. J. Chem. 1997, 75, 1174.

17. (a) Onishi, I.; Ohshima, S.; Fujisawa, S.; Aoki, J.; Ohashi, Y.; Krygowski, T. M. J. Mol. Struct. 1992, 265, 283. (b) Krygowski, T. M.; Ciesielski, A.; Bird, C. W.; Kotschy, A. J. Chem. Inf. Comput. Sci. 1995, 35, 203. (c) Schleyer, P.v.R.; Jiao, H. Pure Appl. Chem. 1996, 68, 209. (d) Cyrański, M. K.; Krygowski, T. M. J. Chem. Inf. Comput. Sci. 1996, 36, 1142.

18. Cyrański, M.; Krygowski, T. M. Tetrahedron 1996, 52, 13795.

19. Młochowski, J. In Chemistry of Heterocyclic Systems (in polish); PWN Press: Warsaw, 1994.

20. Frisch, M. J.; Trucks, G. W.; Schlegel, H. B.; Scuseria, G. E.; Robb, M. A.; Cheeseman, J. R.; Zakrzewski, V. G.; Montgomery, Jr., J. A.; Stratmann, R. E.; Burant, J. C.; Dapprich, S.; Millam, J. M.; Daniels, A. D.; Kudin, K. N.; Strain, M. C.; Farkas, O.; Tomasi, J.; Barone, V.; Cossi, M.; Cammi, R.; Mennucci, B.; Pomelli, C.; Adamo, C.; Clifford, S.; Ochterski, J.; Petersson, G. A.; Ayala, P. Y.; Cui, Q.; Morokuma, K.; Malick, D. K.; Rabuck, A. D.; Raghavachari, K.; Foresman, J. B.; Cioslowski, J.; Ortiz, J. V.; Baboul, A. G.; Stefanov, B. B.; Liu, G.; Liashenko, A.; Piskorz, P.; Komaromi, I.; Gomperts, R.; Martin, R. L.; Fox, D. J.; Keith, T.; Al-Laham, M. A.; Peng, C. Y.; Nanayakkara, A.; Gonzalez, C.; Challacombe, M.; Gill, P. M. W.; Johnson, B.; Chen, W.; Wong, M. W.; Andres, J. L.; Gonzalez, C.; Head-Gordon, M.; Replogle, E. S.; Pople, J. A., Gaussian, Inc. Pittsburgh PA, 1998.

21. This work

22. Petricek, V.; Cisarova, I.; Hummel, L.; Kroupa, J.; Brezina, B. Acta Cryst. B 1990, 46, 830.

23. Cyrański, M. K.; Schleyer, P. v. R.; Krygowski, T. M.; Jiao, H.; Hohlneicher, G. Tetrahedron 2003, 59, 1657.

24. Gimarc, B. M., J. Am. Chem. Soc. 1983, 105, 1979.

25. Minkin, V. I.; Glukhovtsev, M. N.; Simkin, B. Ya. Aromaticity and AntiaromaticityElectronic and Structural Aspects; Wiley: New York, 1994. 
26. Kloc, K.; Młochowski, J. Roczniki Chemii 1975, 49, 1621.

27. Sheldrick, G. M. Acta Crystallogr. 1990, A46, 467.

28. Sheldrick, G. M., SHELXL93. Program for the Refinement of Crystal Structures., Univ. of Göttingen: Germany.

29. International Tables for Crystallography, Wilson, A. J. C. Ed.; Kluwer: Dordrecht, 1992; Vol. C. 